\title{
Generation of Spurious X-rays by Focused Ion Beams in Dual Beam Instruments
}

\author{
J.J. Evertsen, ${ }^{*}$ M. Toth, ** B.L. Thiel, ${ }^{*}$ and E. Lifshin* \\ * College of Nanoscale Science and Engineering, University at Albany, 255 Fuller Road, Albany, \\ NY 12203, USA \\ ** FEI Company, Hillsboro, Oregon, USA
}

Recent work suggests that irradiation by a $30 \mathrm{keV} \mathrm{Ga}^{+}$focused ion beam (FIB) produces characteristic x-ray emission from various target materials [1]. The x-ray yield was shown to be greatest in the case of insulators. [1] In the present study it is argued that such spectra are artifacts produced by tertiary electrons accelerated by the electric field generated by excess charge. The x-ray generation volume is highly delocalized, and can not be used to perform microanalysis.

We start by considering x-ray emission from a grounded metal. Experimentally determined x-ray cross-sections for $30 \mathrm{keV} \mathrm{Ga}{ }^{+}$ions in $\mathrm{Cu}$ are in the range of $10^{-25}$ to $10^{-26} \mathrm{~cm}^{2}$ [2], roughly 5 orders of magnitude lower than that for electrons of equivalent energies [3]. To put this in perspective, these numbers imply that if a $10 \mathrm{nA}$ electron beam generates $10^{6}$ counts per second (cps) with a given detector configuration, a $10 \mathrm{nA} \mathrm{Ga}{ }^{+}$beam would produce around 10 cps- well under the noise threshold of most commercial detectors. Any spectra that contain significantly more counts must be due to another source. In the case of non-conductors, one possible source of spurious x-rays is tertiary electrons emitted when secondary or backscattered ions strike surfaces around the sample. $\mathrm{Ga}^{+}$irradiation gives rise to positive charging, creating an electric field between the sample and the pole piece of the electron column, which is the closest piece of grounded metal in a typical coincident dual-beam system. The field will accelerate positive ions emitted from the sample, and tertiary electrons emitted from the pole piece. The electrons will impact the sample with an energy equal to $\left[E_{e}-q V_{s}\right.$ ], where $E_{e}$ is the electron emission energy, $q$ is the charge of an electron and $V_{s}$ is the sample surface potential. The resulting $\mathrm{x}$-ray spectra will be governed by $\mathrm{V}_{\mathrm{s}}$ (i.e., charging).

To test this hypothesis an alumina sample was irradiated with $2 \mathrm{nA}$ of $30 \mathrm{keV} \mathrm{Ga}{ }^{+}$ions in a Zeiss $1540 \mathrm{XB}$ dual beam instrument, equipped with a PGT energy dispersive x-ray detector. The spectrum shown in figure 1 was obtained, which indeed shows Al- and O-K $\alpha$ peaks with good counting statistics, but also exhibits a background characteristic of electron irradiation. That is, a relatively high Bremsstrahlung [3]. To determine if the x-ray emission is due to tertiary electrons, an electrically isolated $3 \times 3 \mathrm{~mm}^{2}$ piece of $\mathrm{Cu}$ tape was centered on alumina. The $\mathrm{Cu}$ was then bombarded with $\mathrm{Ga}^{+}$ions under the same conditions as above, producing the spectrum shown in figure 2. Again this looks similar to what would be expected under electron-beam bombardment except for the presence of the $\mathrm{Al}$ and $\mathrm{O}$ peaks. The sample is sufficiently thick to prevent $\mathrm{Ga}^{+}$or even electrons from penetrating through to the substrate. In this spectrum, the Duane-Hunt limit was found to be about $10 \mathrm{keV}$. Next, a grounded tungsten in-situ specimen preparation needle was put in contact with the sample to discharge the copper and the spectrum in Figure 3 was collected. Some counts are present in this spectrum but the full scale peak is only 9 counts versus 1100 counts in the floating case. This strongly suggests that the majority of the x-rays shown in figures 1 and 2 were created by tertiary electrons, rather than the incident $\mathrm{Ga}^{+}$ions. 
To support this point further, the steady state electric field between the pole piece and the $\mathrm{Cu}$ was modeled using QuickField ${ }^{\mathrm{TM}} 5.0$ (www.quickfield.com.) software. The copper piece was assigned a potential of $5 \mathrm{kV}$, based on the typically observed value of the Duane-Hunt limit. Figure 4 shows the equipotential lines between the sample and the pole piece. An electron created at point 1 would be accelerated by the field to the copper, striking it with $5 \mathrm{keV}$ of kinetic energy. Conversely, an electron emitted from point 2 would be brought by the field to the alumina substrate, offering a possible explanation for the presence of the $\mathrm{Al}$ and $\mathrm{O}$ peaks in Figure 2 [4].

References

[1] L.A. Giannuzzi, Scanning, Vol. 27, (2005) 165.

[2] G.M. McCracken, Rep. Prog. Phys. 38 (1975) 241.

[3] J.I. Goldstein et al., Scanning Electron Microscopy and X-ray Microanalysis, Plenum, New York, 1992.

[4] Thanks to Vasiliki Tileli for help with QuickField ${ }^{\mathrm{TM}}$ and to the Interconnect Focus Center for partial funding of this work.

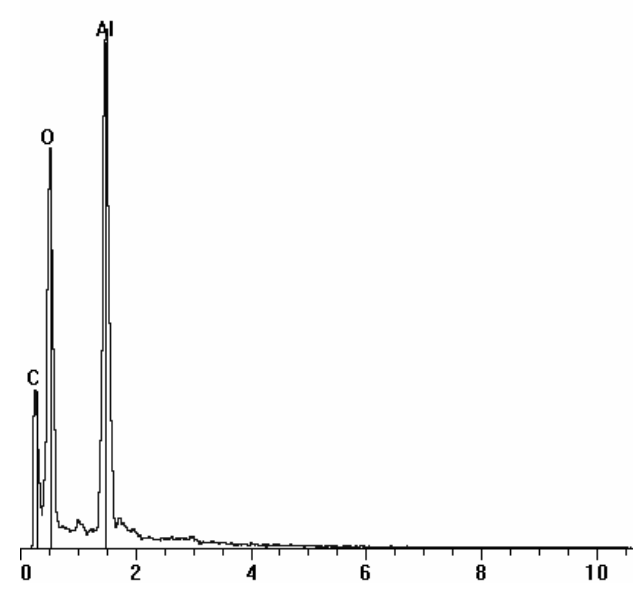

Fig 1. 100s live time EDS spectrum of $\mathrm{Al}_{2} \mathrm{O}_{3}$ created with $2 \mathrm{nA} 30 \mathrm{keV} \mathrm{Ga}{ }^{+}$ions. 5400 counts full scale.

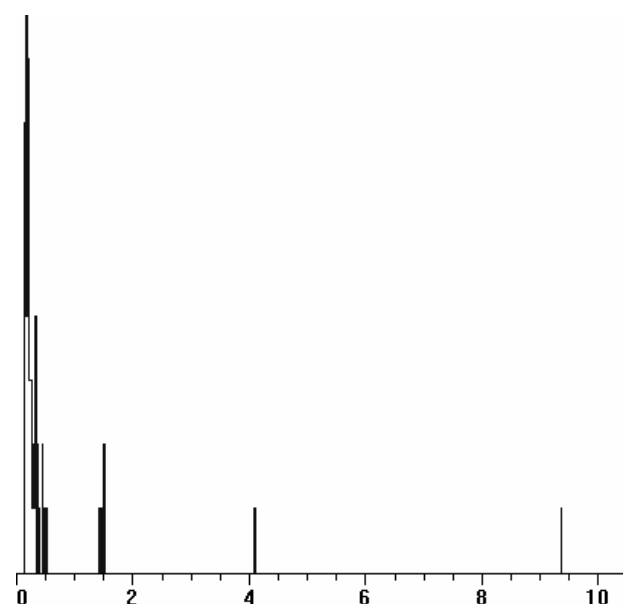

Fig 3. 100s live time EDS spectrum of grounded $\mathrm{Cu} / \mathrm{Al}_{2} \mathrm{O}_{3}$ created with $2 \mathrm{nA}$ $30 \mathrm{keV} \mathrm{Ga}^{+}$ions. 9 counts full scale.

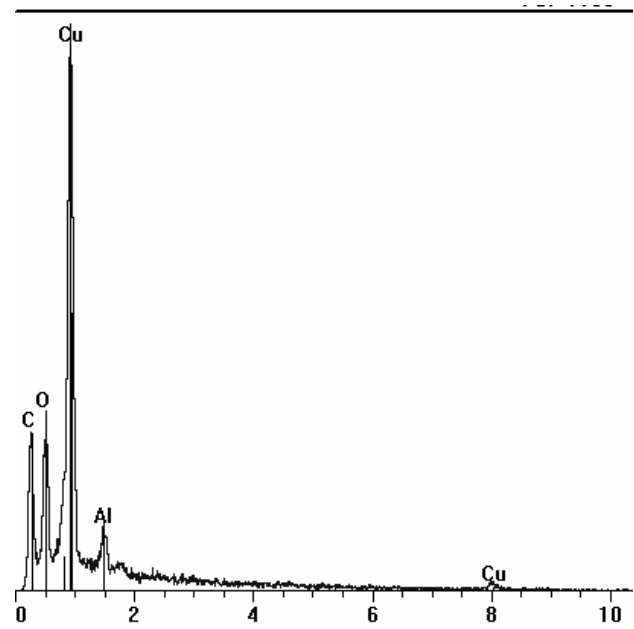

Fig 2. 100s live time EDS spectrum of floating $\mathrm{Cu}$ on $\mathrm{Al}_{2} \mathrm{O}_{3}$ created with $2 \mathrm{nA}$ $30 \mathrm{keV} \mathrm{Ga}^{+}$ions. 1100 counts full scale.

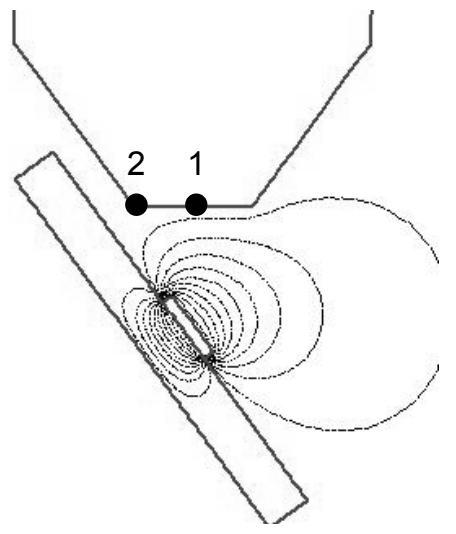

Fig 4. Quick Field output showing $500 \mathrm{~V}$ equipotential lines created between the pole piece and a floating metal sample. Floating $\mathrm{Cu}$ piece was assumed to have a potential of $5 \mathrm{kV}$ 